\title{
Evaluation of Land Resources Carrying Capacity in Harbin
}

Rong GUO, School of Architecture, Harbin Institute of Technology, Key Laboratory of Cold Region Urban and Rural Human Settlement Environment Science and Technology, Ministry of Industry and Information Technology, Harbin 150006, China

Ye GAO, School of Architecture, Harbin Institute of Technology, Key Laboratory of Cold Region Urban and Rural Human Settlement Environment Science and Technology, Ministry of Industry and Information Technology, Harbin 150006, China

Yujing BAI, School of Architecture, Harbin Institute of Technology, Key Laboratory of Cold Region Urban and Rural Human Settlement Environment Science and Technology, Ministry of Industry and Information Technology, Harbin 150006, China

\begin{abstract}
The land is a natural resource and material carrier for human survival. As a kind of resource, it is the most basic and essential guarantee in the process of human production and life development. The carrying capacity of land resources is the support capacity of land resources to population and human social-economic activities in a particular area during a specific period. The evaluation of the carrying capacity of land resources is helpful for effectively formulating the development plan of land resources, which is of great practical significance to promote the sustainable use of land resources. Based on the Harbin data of urban economic and social development and land resource development, this paper establishes an evaluation system of land resource carrying capacity for Harbin, which includes two systems: land pressure and land support. Each subsystem contains multiple indicators from the four aspects of economy, society, ecology and construction. It uses the land carrying rate model to evaluate the land resource carrying capacity of Harbin from 2000 to 2015. The results show that during the period 2000-2015 the carrying, the pressure of land resources in Harbin is increasing year by year. The supporting capacity of the land is also growing, and its growth rate is a little greater than the growth rate of carrying pressure. The carrying capacity of land resources in Harbin is at a reasonable and moderate level and has some carrying potential.
\end{abstract}

\section{Keywords}

Carrying capacity of land resources, Evaluation system, Sustainable land use, Harbin

\section{Introduction}

The land is an irreplaceable resource, a material necessary for human survival and development, and it occupies a core position among numerous resources. In the rapid growth of urbanization, the land is being developed and used, some of which are excessive development and waste of resources. As a result, the urban has experienced deteriorating living environment, fragile ecological environment and excessive consumption of resources. Sustainable use of land resources and economical use of resources has become the consensus of the people of the world. Therefore, the analysis and understanding of land 
carrying capacity is an accurate observation of land conditions. It will facilitate the protection and restoration of resources and sustainable development.

There are many methods to evaluate the carrying capacity of land resources, including the evaluation of single resources such as land, water and mineral resources, the evaluation of single goals such as land productivity and land suitability, and the evaluation of multiple purposes. At present, more studies tend to conduct a comprehensive evaluation of various aspects.

The carrying capacity of land resources can usually be expressed as the support capacity of the land for human economic and social activities on the land.This study uses a comprehensive research method of land carrying capacity, which constructs the evaluation index system of land resource carrying capacity for Harbin from multiple perspectives, such as society, economy, ecology and urban construction. It uses the land carrying rate model to calculate the index, and finally obtains the pressure on land resources, the supporting capacity, and the overall carrying capacity.

Based on the characteristics of the urban system, it uses the analysis of the pressure on the land and the support to construct an evaluation system, conduct evaluation and analysis. It understood the land carrying capacity of Harbin. It provides a basis for decision-making on the intensity and scale of future development and construction. It also has guiding significance for the protection and rational development of land resources.

\section{Research area and methodology}

In this research, Harbin was selected as the research area. It built a comprehensive evaluation index system for land resources. The ecological carrying rate model was chosen to calculate various indicators. The land resource carrying capacity of Harbin from 2000 to 2015 was obtained.

\subsection{Overview of the research area}

Harbin is the capital of Heilongjiang Province. It is located in the northeastern part of China's Northeast Plain, in the south of Heilongjiang Province, and the centre of Northeast Asia. It is an important hub for the first Eurasian land bridge and air corridor. The total area of Harbin is 53,000 square kilometers, of which the urban area is 7,086 square kilometers. According to statistics, in 2015, it had 428 square kilometers of construction land and a non-agricultural population of 4.9 million. The regional product value is 534.01 billion yuan, and the per capita local product value reaches 53,872 yuan. The social and economic development trend is good.

\subsection{Research Method}

According to the definition of land resource carrying capacity, the land carrying capacity depends on the two forces, land pressure and land supporting capacity. Based on relevant research results and experience, it constructs the evaluation system of land resource carrying capacity for Harbin, including an evaluation index system and evaluation model.

\subsubsection{The evaluation index system}

The evaluation index system of land resource carrying capacity is based on careful consideration of land resources. It evaluates the land carrying capacity from many aspects. Its fundamental purpose is to understand the carrying capacity of land resources fully. Therefore, to construct an evaluation index system, it is necessary to objectively reflect the degree of coordination between land resources and economic, social, ecological and construction conditions. Based on the actual situation of data acquisition, the construction of Harbin's land resource carrying capacity evaluation index complies with the following 
three principles: (1) The carrying capacity of land resources is the carrying capacity of land resources for human activities and the capacity of the services that land resources can provide. Therefore, the index system must reflect the ability of land resources. (2) As a resource, the land has a specific particularity. Its carrying capacity is, directly and indirectly, related to various aspects such as social, economy and ecology. The evaluation index system needs to be comprehensive. (3)The land is a complex system that has hierarchical characteristics. Different land types and functions exhibit other carrying capacity characteristics. The index system should have distinct hierarchical features.

Based on the above analysis, combined with the use of land resources in Harbin, by referring to the current research results and methods, it builds an evaluation index system. Query and sort out the "Harbin Statistical Yearbook" from 2000 to 2015, obtain the required data, standardize the index data, determine the weight, and finally complete the land resource carrying capacity evaluation index system for Harbin (Table 1).

Table1. Evaluation Index System of Harbin Land Resource Carrying Capacity.

Source: Author self-painted

\begin{tabular}{|c|c|c|c|c|}
\hline Target level & Subsystem level & Criteria level & Index level & Index weight \\
\hline \multirow{19}{*}{$\begin{array}{l}\text { Land } \\
\text { resource } \\
\text { carrying } \\
\text { capacity }\end{array}$} & \multirow{10}{*}{$\begin{array}{l}\text { Land pressure } \\
\text { system }\end{array}$} & \multirow{2}{*}{ Economic } & GDP per capita & 0.079 \\
\hline & & & Unit construction land investment & 0.039 \\
\hline & & \multirow{3}{*}{ Society } & Population density & 0.052 \\
\hline & & & The natural population growth rate & 0.020 \\
\hline & & & Engel coefficient & 0.014 \\
\hline & & \multirow{3}{*}{ Ecology } & Industrial waste water discharge & 0.058 \\
\hline & & & Industrial $\mathrm{SO}_{2}$ emissions & 0.058 \\
\hline & & & Industrial smoke and dust emissions & 0.058 \\
\hline & & \multirow{2}{*}{ Construction } & Development intensity & 0.107 \\
\hline & & & Total area & 0.015 \\
\hline & \multirow{9}{*}{$\begin{array}{l}\text { Land support } \\
\text { system }\end{array}$} & \multirow{2}{*}{ economic } & Fixed asset investment per land & 0.119 \\
\hline & & & Contribution rate of tertiary industry & 0.074 \\
\hline & & Society & Urbanization level & 0.107 \\
\hline & & \multirow{4}{*}{ Ecology } & Domestic waste disposal & 0.040 \\
\hline & & & Industrial stable waste utilization rate & 0.032 \\
\hline & & & Forest cover rate & 0.038 \\
\hline & & & Water resources per capita & 0.029 \\
\hline & & \multirow{2}{*}{ Construction } & Green coverage rate of built-up area & 0.022 \\
\hline & & & Unused land area & 0.040 \\
\hline
\end{tabular}

\subsubsection{Evaluation model}


Concerning related research methods, it uses the land carrying rate model to calculate the land carrying capacity of Harbin. The evaluation model is the ratio of land pressure to land supporting capacity, which can be used as a characterization of land bearing capacity. The formula is

$$
L C=\frac{V_{P}}{V_{S}}
$$

Among them, $L C$ is the land carrying rate, $V_{P}$ is the pressure on the land, and $V_{S}$ is the land support. Summarizing the relevant research results and experience, it divides the land carrying rate into three levels,(1) $0 \leq L C<0.5$, the land carrying rate is too low, and the land has a large carrying space, but it has not been well used; (2) $0.5 \leq L C<1$, the land carrying rate is more reasonable, and the smaller the $L C$ value, the larger the land carrying potential space; (3) $L C \geq 1$, the land carrying rate is too high, saturated or overloaded. VP and VS are the sums of all index quantities and weight products.

\section{Results and analysis}

\subsection{Results}

Based on the above evaluation methods and fundamental data of Harbin, we get the land carrying rate, land pressure and land support from 2000 to 2015 in Harbin (Table 2).

Table 2. Evaluation results of land resource carrying capacity in Harbin

\begin{tabular}{ccccc}
\multicolumn{5}{c}{ Source: Author self-painted } \\
\hline \\
\hline Land pressure & 2000 & 2005 & 2010 & 2015 \\
\hline Land support & 0.664 & 0.673 & 0.685 & 0.698 \\
\hline Land carrying rate & 0.815 & 0.828 & 0.847 & 0.867 \\
\hline
\end{tabular}

\subsection{Analysis}

According to the land carrying rate model, the indexes of Harbin's land resource carrying capacity are calculated. Through the analysis of the results, the following products are obtained.

\subsubsection{Land pressure}

From 2000 to 2015, Harbin's land pressure index changed between 0.664 and 0.713 , showing a state of improvement. However, the upward trend is relatively flat, without much fluctuation. This shows that the pressure on the land in Harbin has been increasing year by year, but the speed has been flat.

\subsubsection{Land support}

The land support index varies from 0.815 to 0.886 , with an average annual growth rate of $1.97 \%$, showing an increasing trend. There was a significant improvement in 2010, and then it levelled off because the area and population of Harbin increased by a certain leap in 2010 due to administrative divisions.

\subsubsection{Land resource carrying capacity}

It can be seen from the table that from 2000 to 2015, the land carrying rate of Harbin changed from 0.815 to 0.805 , with an average of 0.8105 . The overall land carrying rate showed a downward trend. According to the grade of land carrying rate, LC was between 0.5 and 1 , the land carrying situation is 
moderate and reasonable, and has some potential. The current supporting capacity of Harbin land can meet the use and pressure of land resources, and the growth rate is slightly higher than the pressure growth rate, indicating that Harbin land still has particular potential.

\section{Conclusion}

In this study, the evaluation system of Harbin's land resource carrying capacity including the two subsystems of land pressure and land support capacity was constructed from the four aspects of the economy, society, ecology and urban construction. Through the calculation method of land carrying rate model, the land resource carrying capacity of Harbin was calculated. The force was evaluated. The evaluation results show that the land carrying rate of Harbin City has declined year by year from 2000 to 2015 , with an average value of 0.815 , which is within a reasonable range of $0.5-1$. The pressure and support of the land are increasing year by year. The growth rate is greater than the pressure, so the carrying capacity of Harbin's land is growing slowly, indicating that it can support the current economic, social, ecological and construction activities of Harbin and has a certain potential. This study uses standard methods for calculating land carrying capacity but adds to the constructed index system to make it more comprehensive to evaluate the land carrying capacity. However, this research mainly adopts qualitative methods in the weight of indicators. It is expected that more quantitative methods can be applied to complete this evaluation in future research.

\section{References}

Li Meng-bo. 'Comprehensive evaluation on the bearing capacity of land resources in Zhangjiakou City', Journal of Hebei Institute of Architecture and Civil Engineering, 34(2),p52-57.

HE Ruhai, RUAN Mengya, CHENG Yuqi, WANG Qishuai. 'Comprehensive evaluation on land resources carrying capacity for Wuhu city', Journal of Anhui Agricultural University,46(3), p471-477.

KRAUSMANN F, HABERL H, SCHULZ N B, et al. 'Land-use change and socio-economic metabolism in Austria: Part I: driving forces of land-use change: 1950-1995', Land Use Policy,20(1), p1-20.

Rong Guo, Tong Wu, Mengran Liu, Mengshi Huang, Luigi Stendardo and Yutong Zhang. 'The Construction and Optimization of Ecological Security Pattern in the Harbin-Changchun Urban Agglomeration, China', International Journal of Environmental Research and Public Health, 2019,16,p1190.

Wenzhu Luo, Yitian Ren,Liyin Shen, Mengcheng Zhu, Yiman Jiang, Conghui Meng, Panxing Zhang. 'An evolution perspective on the urban land carrying capacity in the urbanization era of China', Science of the Total Environment, 2020, 744.

Nana Yang,Jiansong Li,Binbin Lu,Minghai Luo,Linze Li. 'Exploring the Spatial Pattern and Influencing Factors of Land Carrying Capacity in Wuhan', Sustainability, 2019, 11(10).

Guangming Cui,Xuliang Zhang,Zhaohui Zhang,Yinghui Cao,Xiujun Liu. 'Comprehensive Land Carrying Capacities of the Cities in the Shandong Peninsula Blue Economic Zone and their Spatio-Temporal Variations', Sustainability,2019,11(2).

Shili Guo,Chunjie Li,Shaoquan Liu,Kui Zhou. 'Land carrying capacity in rural settlements of three gorges reservoir based on the system dynamic model', Natural Resource Modeling ,2018, 31(2).

Hengwei Wang, Jinming Yan,Karima Kourtit, Peter Nijkamp, Jacques Poot. 'Spatial - temporal differentiation of the carrying capacity of cities: a case study of ', Regional Science Policy \& Practice,2014,6(4). 
Sara Johnson, Guangxing Wang, Heidi Howard, Alan B. Anderson. 'Identification of superfluous roads in terms of sustainable military land carrying capacity and environment', Journal of Terramechanics, 2010, 48(2).

Sun Tong, Feng Zhiming, Yang Yanzhao, Lin Yumei, Wu Yanjuan. 'Research on Land Resource Carrying Capacity: Progress and Prospects', Journal of Resources and Ecology, 2018,9(4).

Shili Guo, Chunjie Li ,Shaoquan Liu, Kui Zhou. 'Land carrying capacity in rural settlements of three gorges reservoir based on the system dynamic model', Natural Resource Modeling, 2018, 31(2).

Jin Yeu Tsou, Yanfei Gao,Y uanzhi Zhang, Genyun Sun, Jinchang Ren, Yu Li, Conghe Song, Junxiang Li, Weiqi Zhou, James Campbell, Prasad Thenkabail. 'Evaluating Urban Land Carrying Capacity Based on the Ecological Sensitivity Analysis: A Case Study in Hangzhou, China', Remote Sensing, 2017, 9(6).

IrbaDjaja, Purwanto, P, Sunoko, H. R. v. 'Analysis of Land Carrying Capacity of Tanah Miring District of Merauke Regency', Advanced Science Letters, 2017, 23(3).

Kun Cheng ,Qiang Fu, Song Cui, Tian-xiao Li,Wei Pei, Dong Liu, Jun Meng. 'Evaluation of the land carrying capacity of major grain-producing areas and the identification of risk factors', Natural Hazards, $2017,86(1)$.

Xiaoxuan Wei, Liyin Shen,Zhi Liu, Linyan Luo, Jinhuan Wang, Yang Chen. 'Comparative analysis on the evolution of ecological carrying capacity between provinces during urbanization process in China', Ecological Indicators, 2020,112.

Yi Dan, Zhao Xiao-Min, Guo Xi, Jiang Ye-Feng, Wang Cheng-Liang, Lai Xia-Hua, Huang Xin-Yi, Chen Lei. 'Evaluation of carrying capacity and spatial pattern matching on urban-rural construction land in the Poyang Lake urban agglomeration, China', The journal of applied ecology, 2019,30(2).

Alvan Pahuluan, Tri Retnaningsih Soeprobowati, Hady Hadiyanto. 'ENVIRONMENTAL CARRYING CAPACITY BASED ON LAND BALANCE FOR EVALUATION PLANNING OF SPATIAL AND REGIONAL IN SOLOK REGENCY, WEST SUMATRA', Journal of Ecological Engineering, 2017,18(3).

Huimin Yan, Fang Liu, Jiyuan Liu, Xiangming Xiao, Yuanwei Qin. 'Status of land use intensity in China and its impacts on land carrying capacity’, Journal of Geographical Sciences, 2017,27(4).

Yao Qian,Lina Tang, Quanyi Qiu, Tong Xu, Jiangfu Liao. 'A Comparative Analysis on Assessment of Land Carrying Capacity with Ecological Footprint Analysis and Index System Method', PLOS ONE, 2015,10(6).

Hou, Maozhang,Chen, Wenjun. 'A Study on Land Carrying Capacity of Hunan Province', Advanced Science Letters, 2013,19(9). 